Images in Neurology

The Saddle and the Horse's Tail

\title{
Cauda Equina Syndrome
}

Tom Theys, MD, PhD; Kuan H. Kho, MD

The cauda equina syndrome is a clinical diagnosis usually requiring immediate surgical treatment to prevent long-lasting neurological sequelae. A 33-year-old woman with a 2-week history of left-sided leg pain and perianal hypoesthesia was referred to us when urinary retention and fecal incontinence developed. The clinical diagnosis of cauda equina syndrome was made. Imaging revealed an intraspinal mass filling up the entire spinal canal at the L5-S1 level (Figure 1).

The patient underwent a laminectomy, which revealed a massive disc herniation with compression and displacement of the thecal sac (Figure 2). Postoperatively, sciatica disappeared and sphincter function clearly improved. However, at 3-month followup, the patient still complained of saddle hypesthesia with important sexual dysfunction and sporadic stress incontinence.

\section{Discussion}

It was the French anatomist André du Laurens (also known as Andreas Lazarius, 1558-1609) who coined the term cauda equina (horse's tail) to refer to the collection of dorsal and ventral

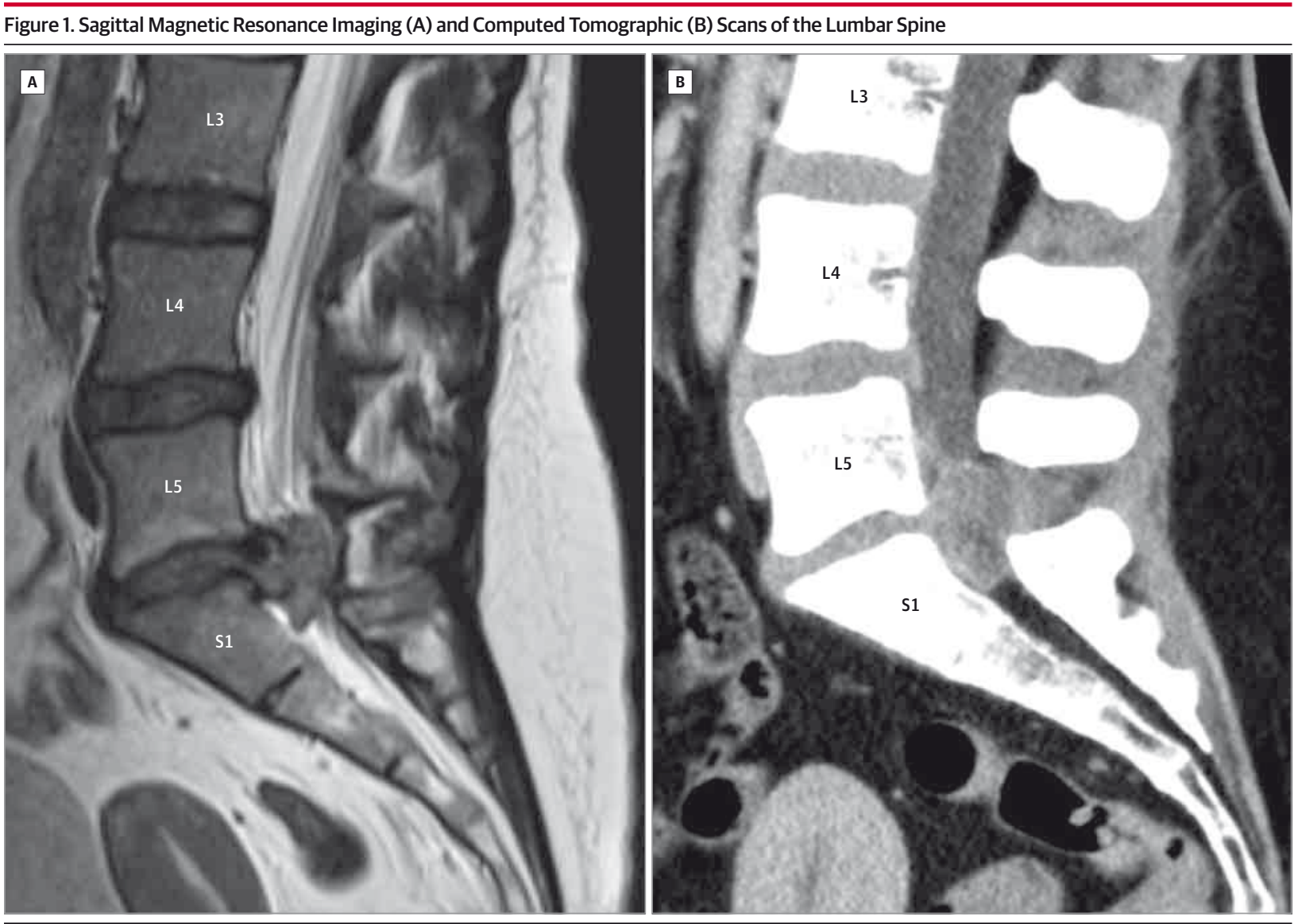

Obliteration of the spinal canal due to L5-S1 disc herniation. 


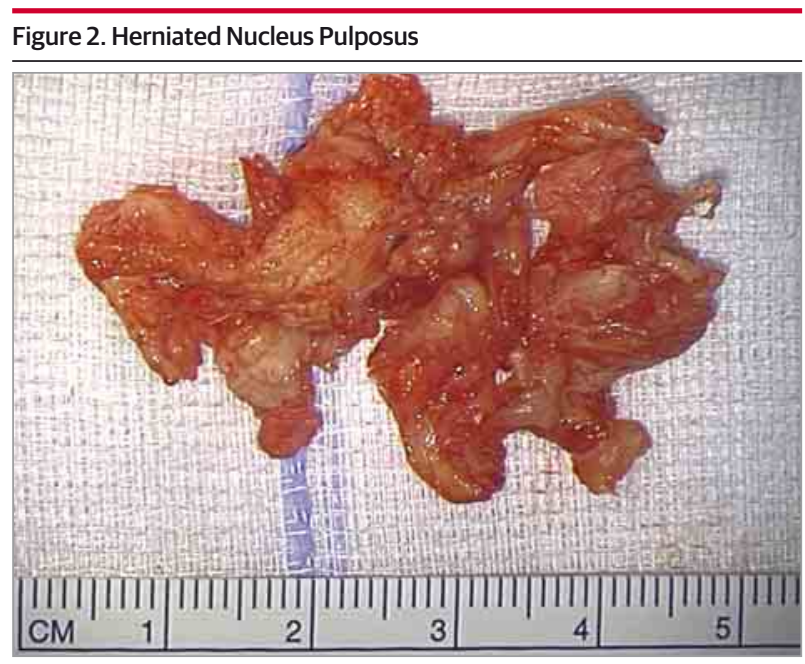

lumbar, sacral, and coccygeal roots surrounding the filum. ${ }^{1}$ Mixter and $\mathrm{Barr}^{2}$ were the first to describe the cauda equina syndrome resulting from compression on the cauda equina. As illustrated by this case, cauda equina syndrome has saddle anesthesia and urinary retention as the main presenting symptoms (Box), with a
Box. Cauda Equina Syndrome (adapted from Lavy et al ${ }^{3}$ )

Main symptoms

Saddle anesthesia

Sphincter or sexual dysfunction

Associated symptoms

Back pain and/or sciatica

Sensory changes, weakness, and/or diminished reflexes in the lower limbs

herniated lumbar disc as the most common etiology. ${ }^{3}$ Other causes include trauma, neoplastic disease, infection or inflammation, vascular anomalies, or spinal hematoma. In the case of urinary retention, the prognosis is worse. ${ }^{3}$

Recognition of cauda equina syndrome, obtaining an appropriate medical history, and a neurological examination are of critical importance and must then lead to prompt action (ie, immediate imaging and surgical therapy). Of equal importance is good communication with the patient, as well as communication among physicians and nursing personnel to prevent medicolegal problems. ${ }^{4}$

\section{ARTICLE INFORMATION}

Author Affiliations: Department of Neurosurgery, University Hospitals Leuven, Leuven, Belgium (Theys, Kho); Department of Neurosurgery. Medisch Spectrum Twente, Enschede, the Netherlands (Kho).

Corresponding Author: Kuan H. Kho, MD, Department of Neurosurgery, Medisch Spectrum Twente, PO Box 50 000, 7500 KA Enschede, the Netherlands (k.kho@mst.nl).
Published Online: May 5, 2014.

Conflict of Interest Disclosures: None reported.

\section{REFERENCES}

1. Olry R, Haines DE. Between André Du Laurens' horse tail and William Cadogan's pony tail. $J$ Hist Neurosci. 2012;21(3):327-331.

2. Mixter WJ, Barr JS. Rupture of the intervertebra disc with involvement of the spinal canal. N Engl J
Med. 1934;211:210-215. doi:10.1056 /NEJM193408022110506.

3. Lavy C, James A, Wilson-MacDonald J, Fairbank J. Cauda equina syndrome. BMJ. 2009;338:b936.

4. Kostuik JP. Medicolegal consequences of cauda equina syndrome: an overview. Neurosurg Focus. 2004;16(6):e8. 